\title{
Equity Style Payoffs And Stock Return Predictability: Evidence From The South African JSE Securities Exchange
}

Kathleen Hodnett, PhD, University of the Western Cape, South Africa Heng-Hsing Hsieh, PhD, CFA, University of the Western Cape, South Africa Paul van Rensburg, PhD, University of Cape Town, South Africa

\begin{abstract}
This paper undertakes to examine the structure of the payoffs to style attributes on the JSE Securities Exchange over the period from 1997 to 2007. Adopting the methodology of Haugen and Baker (1996), two expected return multifactor models are constructed to predict forward monthly returns of sample stocks using style attributes as model inputs. The Grinold model has an objective of selecting model inputs that will maximize the in-sample Grinold (1989) information ratio while the QH model has an objective of maximizing the in-sample Qian and Hua (2003) information ratio. The out-of-sample predictions of the models and their corresponding model inputs are evaluated over the period from 2002 to 2007. The permutations of the style attributes for the models are updated every 12 months based on training over the prior 60 months under the stepwise variable selection procedure proposed by Van Rensburg and Robertson (2003). The examination of the style attributes selected by the respective models reveal that most of the style attributes that exhibit significant univariate mean payoffs in our prior study are selected by the expected return multifactor models in this research. In addition, the value attributes with the most consistent univariate payoffs are found to be the most important contributors to equity return forecasting. It is also found that models that account for multicollinearity tend to outperform the models that fail to address this issue over the out-of-sample period. Overall, the QH model outperforms the Grinold model in terms of both information ratios over the out-of-sample period. The out-of-sample performance scores of the respective models are consistent with their corresponding in-sample performance scores, which suggest that successful expected return multifactor models, based on style attributes, can be developed to forecast ex-ante JSE equity returns.
\end{abstract}

Keywords: Style Attributes Efficient Market Hypothesis; Style Anomalies; Size Effect; Value Effect; Momentum Effect; Style Payoffs; Asset Pricing Models; Expected Return Factor Models; Information Ratio

\section{INTRODUCTION}

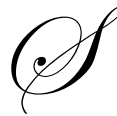

tyle attributes are firm-specific variables ranging from price and volume data to accounting ratios that are crucial information to asset managers who follow specific investment styles such as value, growth or momentum investing. Although this practice contradicts capital market theories in that no abnormal economic benefit is available to investors in perfectly efficient capital markets, empirical studies find that the capital asset pricing model (CAPM) does not adequately explain the returns of the portfolios formed based on style attributes. While Fama and French (1993) argue that the CAPM fails to incorporate premiums on the risks inherent in the style-based investment strategies, Daniel and Titman (1997) suggest that multifactor models that use the actual style attributes rather than the risk premiums as model inputs are better able to explain variations in stock returns. Based on the argument of Daniel and Titman (1997), Haugen and Baker (1996) construct expected return multifactor models that employ the actual style attributes to forecast the monthly forward stock returns. The empirical studies on the capital market anomalies relating to style attributes and the asset pricing models that attempt to explain these anomalies are discussed in the literature review section. 
This paper extends our earlier study on the univariate style payoffs by conducting multivariate analysis on the payoffs to equity investment styles on the JSE Securities Exchange (JSE) over the period from 1997 to 2007 based on the expected return multifactor model of Haugen and Baker (1996). The advantage of the multivariate approach over the univariate approach is that the collective explanatory power of the style attributes, and hence the complementary properties of the attributes can be utilized in forecasting equity returns. The objectives of the analysis includes identifying essential style attributes that consistently differentiate JSE equity returns, and determining the optimal permutations of the style attributes to be employed by the expected return multifactor models. The stepwise variable selection procedure outlined in Van Rensburg and Robertson (2003) is adapted for this purpose. The univariate tests documented in Hodnett, Hsieh and Van Rensburg (2012) are in-sample observations of ex post style payoffs. This paper intends to further the research in this area by investigating the outof-sample robustness of the expected return multifactor models in forecasting the ex-ante JSE equity returns. The details regarding the research sample, pre-specified style attributes for the research and the remedies to the potential research biases are discussed in the data and sample selection section. The detailed discussions on the building of the expected return multifactor models and the stepwise variable selection procedure are presented in the research methodology section.

The ultimate goal of this research is to develop a system that assists South African asset managers in building style-based portfolios based on the expected returns forecasted by the optimal permutations of style attributes. The findings regarding the payoffs to the style attributes on the JSE are analyzed and discussed in the results section. The conclusion section compares and contrasts the main findings of this research to that of our earlier study based on the univariate approach and provides useful insights based on the empirical findings.

\section{LITERATURE REVIEW}

Efficient market anomalies representing patterns in stock prices that cannot be explained by the CAPM of Sharpe (1964) and Lintner (1965) include the size effect, the value effect, the long-term reversal effect and the shortterm momentum effect. The size effect refers to the situation where firms with small market capitalizations (small firms) outperform firms with large market capitalizations (Banz (1981), Keim (1983), Reinganum (1983), Blume and Stambaugh (1983) and Fama and French (1992)). The value anomaly refers to the situation where firms with high ratios of fundamental values relative to share prices, for example, high book-to-market (B/M), high cash flowto-price $(\mathrm{C} / \mathrm{P})$, high earnings-to-price (E/P or earnings yield), high dividend-to-price (D/P or dividend yield), to name a few, outperform firms with low ratios of fundamental values relative to share prices (Basu $(1977,1983)$, Litzenberger and Ramaswamy (1979), Fama and French (1992) and Rosenberg, Reid and Lanstein (1995)). The long-term (reversal) and short-term momentum effect arises as a result of anomalies relating to past stock returns. Portfolios based on past stock returns (short-term and long-term) yield abnormal returns when used as explanatory variables in the cross-section of returns (De Bondt and Thaler (1985, 1987), Jegadeesh and Titman (1993, 2001)). While some adopt a risk-based approach when explaining the anomalies (Fama and French (1992, 1993, 1996, 1998)), others advocate that the anomalies are actually the consequence of the irrational behavior of investors (Chopra, Lakonishok and Ritter (1992), Lakonishok, Shleifer and Vishny (1994) and Haugen, (1995)).

Much debate has arisen between academics and practitioners, alike, regarding the factors which explain the cross-sectional equity returns. Fama and French (1992) argue that size (as measured by market capitalization) and value $(\mathrm{B} / \mathrm{M})$ represent the primary factors that subsumes the influences of all other factors in explaining crosssectional equity returns. Fama and French (1993) propose a three-factor model that uses the market risk premium of the CAPM and risk premiums on the size (proxied by market capitalization) and value (proxied by B/M) as model inputs to explain portfolio returns formed by market anomalies such as E/P, D/P C/P. They find that the three-factor model effectively explains most of the prior documented market anomalies. They conclude that since prior anomalies are proxied by firm-specific attributes of price multiples, it is expected that the effect of some attributes are subsumed by the effects of more important attributes such as market capitalization and B/M. As a result the size and value risk premiums can be viewed as the missing factors of the CAPM. The short-term momentum effect of Jegadeesh and Titman (1993) is the only anomaly that Fama and French (1993) is not able to explain. Fama and French (1996) argue that the short-term momentum effect is as a result of biases in asset pricing (data-snooping or survivorship biases). Fama and French (1996) support this risk-based view of Fama and French (1993) and explain that poor performing small stocks having high $\mathrm{B} / \mathrm{M}$ ratios are vulnerable to financial distress and thus require a distress premium. 
Another view of the discovered market anomalies is that investors make irrational forecasts which are due to psychological biases. By examining the behavior of investors, researchers have identified and examined biases that impact on investment performance. For example, De Bondt and Thaler $(1985,1987)$ test the overreaction hypothesis where they assert that irrational investors persistently overweigh recent information and underweigh long-term fundamental information. As a result, the contrarian and momentum asset pricing anomalies arise. The over- or understated asset prices are expected to correct to its long-term value, given that the long-term fundamentals remain the same. Advocates in support of this view include Jegadeesh and Titman (1993), Barberis, Shleifer and Vishny (1998) and Daniel, Hirshleifer and Subrahmanyam (1998). According to Chopra, Lakonishok and Ritter (1992), Lakonishok, Shleifer and Vishny (1994) and Haugen (1995), differentials in predicted returns come as a surprise to investors and irrationality causes naïve investors to incorrectly estimate value and glamour stocks' future growth prospects, becoming overly optimistic about glamour stocks and overly pessimistic about value stocks. Daniel and Titman (1997), on the other hand, argue that the value premium could be attributed to a behavioural explanation that is not based on investor overreaction, but rather one that traces the actual attribute characteristics themselves. Daniel and Titman (1997) argue that it is the actual market capitalization and B/M attribute characteristics, and not the risk premiums on the small and value stocks that explain the cross-sectional equity returns. They thus argue in favour of a multifactor model that uses a combination of attribute characteristics as model inputs, as opposed to the size and value risk premiums, to explain the cross-sectional equity returns.

Based on the argument of Daniel and Titman (1997), Haugen and Baker (1996) test the validity of the combinations of style attributes that include approximately 50 measures of accounting information and past return behavior to determine which attributes explain equity returns in the United States of America, United Kingdom, Japan, Germany and France respectively, over the period from 1979 to 1993. These attributes are categorized into risk factors, liquidity factors, price level factors, growth potential factors and price history factors. The results reveal that the signs and the relative significance of the payoffs to the style attributes are consistent over sub-periods. The results of the out-of-sample tests support the use of the characteristic approach suggested by Daniel and Titman (1997) in predicting returns in the respective countries. In a follow-up study, Haugen and Baker (2009) extend the application of their original study to a longer period spanning 44 years from 1963 to 2007. The results are consistent with the results of the original study.

With regard to South African studies, Achour, Harvey, Hopkins and Lang (1999) examine 28 style attributes on the JSE over the period from 1993 to 1998. The in-sample period spans the period from 1993 to 1995, while the out-of-sample period spans the period from 1996 to 1998. For each attribute, sample stocks are ranked in order of expected returns forecasted by their respective attribute values. The style attributes under examination are categorized into fundamental factors, expectation factors, technical factors and size factors. The results indicate that $\mathrm{E} / \mathrm{P}$ and earnings forecast revisions yield the highest average excess returns, while $\mathrm{B} / \mathrm{M}$ yields the lowest average excess returns. Momentum attributes are not found to be significant in this study.

Van Rensburg and Robertson (2003) conduct regression analysis on stock returns using 24 style attributes, by adopting the characteristic approach of Daniel and Titman (1997) on the JSE over the period from 1990 to 2000. Style attributes with significant payoffs are then used in a stepwise permutation procedure. Attributes are added to the multifactor model until the explanatory power of the multifactor model ceases to improve. Although the results of the univariate test reveals evidence of the size and value effects, the results of the multivariate analysis suggest a two-factor model with size (market capitalization) and price-earnings ratio as model inputs that best explain the cross-sectional JSE returns. In line with Achour, Harvey, Hopkins and Lang (1999), none of the momentum factors are significant. Van Rensburg and Robertson (2004) adopt the methodology of Daniel and Titman (1997) and Daniel, Titman and Wei (2001) on the JSE and form simulated quintile portfolios over the period from 01 July 1990 to 30 June 2000. The objective of this study is to determine whether the loadings on factor mimicking portfolios or the direct attribute characteristics best explain the cross-sectional JSE returns. The results reveal that the crosssection of returns on the JSE are better explained using the direct attribute characteristics rather than factor loadings.

Hodnett, Hsieh and Van Rensburg (2012) analyze the univariate payoffs to style attributes on the JSE over the period from 1997 to 2007. Style attributes under examination are divided into five categories namely, fundamental values relative to share price, solvency and liquidity, fundamental growth, size and return momentum and consensus analyst forecast. The results reveal that style attributes from all categories receive significant payoffs 
with the exception of the style attributes from the solvency and liquidity category. More specifically, stocks with higher fundamental values relative to the stock prices, higher dividend and earnings growth, lower market capitalization, higher short-term returns and higher earnings forecasts tend to generate higher returns in the forward month over the examination period.

Research on the examination of style attributes also extends to other emerging economies. For example, Serra (2003) adopts the methodology of Haugen and Baker (1996) across emerging economies (including South Africa) in order to determine if the attributes that drive returns in emerging economies are consistent with those of developed economies. Important attributes are found to be common across emerging economies and similar to that of the developed economies in this study.

\section{DATA AND SAMPLE SELECTION}

The research sample consists of the stocks comprising the FTSE/JSE All Share Index over the examination period from 01 January 1997 to 31 December 2007. As of 31 March 2009, monthly data of the closing stock prices, indexes and firm-specific attributes for 159 stocks comprising the FTSE/JSE All Share Index are downloaded from DataStream International. Since DataStream International records information directly from published financial statements as they arrive, the database is not subject to look-ahead bias. The 38 style attributes examined by this research are divided into six categories, namely, (I) fundamental values relative to stock price, (II) solvency and liquidity, (III) fundamental growth, (IV) operating performance, (V) size and return momentum and (VI) consensus analyst forecast. With the exception of the style attributes in the operating performance category, all style attributes in the other five categories are adapted from our earlier study. The descriptors of the style attributes are displayed in Table 1.

A turnover ratio for each sample stock in each month is computed by dividing the average number of stocks traded daily for a particular month by the total number of outstanding stocks. Stocks with equal or less than a turnover ratio of $0.01 \%$ are excluded for that month to ensure that there is sufficient liquidity for the stocks in the sample. The issue of survivorship bias is partially addressed through the retention of liquid stocks which are less likely to be non-survivors. In addition, companies involved in corporate restructuring, mergers and acquisitions or share splits are excluded as of the date of the above mentioned corporate event. To remove outliers in each month, style attributes are winsorized by setting the maximum and minimum monthly values of each attribute to the $99.5^{\text {th }}$ and $0.5^{\text {th }}$ percentiles respectively.

After the winsorizing procedure, the monthly cross-section of each style attribute is standardized by first subtracting the monthly cross-sectional mean of each style attribute from the cross-sectional distribution of each style attribute. The cross-sectional distribution of each style attribute is subsequently divided by its respective crosssectional standard deviation. Repeating this procedure monthly enables the monthly distribution of each style attribute to be normally distributed over the examination period. The purpose of standardization is to allow for direct comparison between the magnitudes of the monthly style payoffs. 
Table 1: Computation of Firm-Specific Style Attributes

\begin{tabular}{|c|c|c|c|}
\hline No. & Descriptor & Style Attribute & Computation \\
\hline (I) & \multicolumn{3}{|c|}{ FUNDAMENTAL VALUES RELATIVE TO STOCK PRICE } \\
\hline 1. & BVTP & Book value-to-price & Book Value of Equity / Share Price \\
\hline 2. & CFTP & Cash flow-to-price & Cash Earnings per Share / Share Price \\
\hline 3. & DY & Trailing dividend yield & Ordinary Shareholders' Dividends per Share / Share Price \\
\hline 4. & EY & Trailing earnings yield & EPS / Share Price \\
\hline 5. & SALESTP & Sales-to-price & Sales per Share / Share Price \\
\hline (II) & \multicolumn{3}{|c|}{ SOLVENCY AND LIQUIDITY } \\
\hline 6. & CFTCURRLIABS & Cash flow-to-current liabilities & Net Cash Flow / Current Liabilities \\
\hline 7. & CFTDEBT & Cash flow-to-debt & Net Cash Flow / Total Liabilities \\
\hline 8. & CURRENTRATIO & Current ratio & Current Assets / Current Liabilities \\
\hline 9. & DEBTTMVE & Debt-to-market value of equity & Total Liabilities / Market Value of Equity \\
\hline 10. & DEBTTBVE & Debt-to-book value of equity & Total Liabilities / Book Value of Equity \\
\hline 11. & ICBT & Interest coverage before tax & Profit Before Interest and Tax / Accrued Interest \\
\hline (III) & \multicolumn{3}{|c|}{ FUNDAMENTAL GROWTH } \\
\hline 12. & G12MCPS & 12-month cash holdings growth & $\begin{array}{l}\text { (Current Cash Holdings per Share / Prior 12-Month Cash } \\
\text { Holdings per Share) -1 }\end{array}$ \\
\hline 13. & G12MDPS & 12-month dividend growth & (Current DPS / Prior 12-Month DPS) - 1 \\
\hline 14. & G12MEPS & 12-month earnings growth & (Current EPS / Prior 12-Month EPS) - 1 \\
\hline 15. & G12MGPMARGIN & 12-month gross profit margin growth & $\begin{array}{l}\text { (Current Gross Profit Margin / Prior 12-Month Gross } \\
\text { Profit Margin) }-1\end{array}$ \\
\hline 16. & G12MNPMARGIN & 12-month net profit margin growth & $\begin{array}{l}\text { (Current Net Profit Margin / Prior 12-Month Net Profit } \\
\text { Margin) }-1\end{array}$ \\
\hline 17. & G12MSALES & 12-month sales growth & (Current Sales / Prior 12-Month Sales) - 1 \\
\hline 18. & G24MEPS & 24-month earnings growth & (Current EPS / Prior 24-Month Earnings per Share) - 1 \\
\hline 19. & GROWTH & Dividend growth rate & Return on Equity $*(1$ - Dividend Payout Ratio) \\
\hline (IV) & \multicolumn{3}{|c|}{ OPERATING PERFORMANCE } \\
\hline 20. & GPMARGIN & Gross profit margin & Gross Profit / Sales \\
\hline 21. & NPMARGIN & Net profit margin & Net Profit after Tax / Sales \\
\hline 22. & PAYOUT & Dividend payout ratio & Current Dividend per Share /Current Earnings per Share \\
\hline 23. & ROA & Return on assets & Net Profit Before Tax / Total Assets \\
\hline 24. & ROE & Return on equity & Net Profit After Tax / Ordinary Shareholders' Equity \\
\hline 25. & TATURNOVER & Total asset turnover & Sales / Total Assets \\
\hline (V) & \multicolumn{3}{|c|}{ SIZE AND RETURN MOMENTUM } \\
\hline 26. & LAGLPRICE & Lagged log of market price & Ln (Prior 1-Month Share Price) \\
\hline 27. & LPRICE & Log of market price & Ln (Current Share Price) \\
\hline 28. & LSIZE & Log of market capitalisation & Ln (Market Capitalisation) \\
\hline 29. & MOM1 & 1-month return & (Current Return Index /Prior 1-Month Return Index) - 1 \\
\hline 30. & MOM12 & 12-month return & (Current Return Index / Prior 12-Month Return Index) - 1 \\
\hline 31. & MOM12-1 & Lagged 11-month return & (Prior 1-Month Return Index / Prior 12-Month Return Index) - 1 \\
\hline 32. & MOM24 & 24-month return & (Current Return Index / Prior 24-Month Return Index) - 1 \\
\hline 33. & MOM3 & 3-month return & (Current Return Index / Prior 3-Month Return Index) - 1 \\
\hline 34. & MOM6 & 6-month return & (Current Return Index / Prior 6-Month Return Index) - 1 \\
\hline (VI) & \multicolumn{3}{|c|}{ CONSENSUS ANALYST FORECAST } \\
\hline 35. & EARNREV & Earnings forecast revision & $\begin{array}{l}\text { (Consensus Next EPS Forecast / Consensus Previous EPS } \\
\text { Forecast) }-1\end{array}$ \\
\hline 36. & EG1 & 1-year forward earnings growth & (Consensus Next EPS Forecast / Current EPS) -1 \\
\hline 37. & FOREY1 & 1-year forward earnings yield & Consensus EPS Forecast 1-year Forward \\
\hline 38. & FOREY2 & 2-year forward earnings yield & Consensus EPS Forecast 2-year Forward \\
\hline
\end{tabular}

Adapted from Hodnett (2010)

\section{RESEARCH METHODOLOGY}

This paper attempts to build expected return multifactor models that forecast sample stock returns based on the historical payoffs to the style attributes. Analyzing the historical payoffs to the style attributes and the model's forecasting ability helps in the identification of style attributes that are crucial to pricing equities on the JSE. 
Following the multivariate approach of Haugen and Baker (1996), the monthly cross-sectional payoffs to the style attributes over the examination period from 01 January 1997 to 31 December 2007 are computed using Equation 1.

$$
R_{i, t}=a_{t}+\sum_{j=1}^{J} b_{j, t} \times F_{i, j, t-1}+u_{i, t}
$$

Where:

$\begin{array}{lll}R_{i, t} & = & \text { stock } i \text { 's realized return in month } t ; \\ a_{t} & = & \text { the estimated common constant for the cross-sectional sample stock returns in month } t ; \\ b_{j, t} & = & \text { the payoff to style attribute } j \text { in month } t ; \\ F_{i, j, t-1} & \text { the style attribute } j \text { for stock } i \text { in month } t-1 \text { (that is, at the beginning of month } t) ; \text { and } \\ u_{i, t} & = & \text { the unexplained component of the return for share } i \text { in month } t .\end{array}$

Once the monthly payoffs and the constants of the regressions are estimated, the expected return factor models can be established to forecast the JSE sample stock returns using Equation 2, where the expected payoffs to the style attributes are computed as the time-series mean of the monthly payoffs over the trailing 12 months. This is considered as a necessary step to ensure that a history of the payoffs to the various factors is taken into account due to the fact that the payoffs to the style attributes may be time-varying. Similarly, the expected constant for a particular month is computed by averaging the trailing 12-month constants.

$$
E\left(R_{i, t}\right)=E\left(a_{t}\right)+\sum_{j=1}^{J} E\left(b_{j, t}\right) \times F_{i, j, t-1}
$$

Where:

$\begin{array}{lll}E\left(R_{i, t}\right)= & \text { the expected (forecasted) return of stock } i \text { in month } t ; \\ E\left(a_{t}\right)= & \text { the expected common threshold of the cross-sectional sample stock returns in month } t \\ E\left(b_{j, t}\right)= & \text { the expected payoff to style attribute } j \text { in month } t\end{array}$

For example, to estimate the expected return of sample stocks for January 2002 (the first month in the outof-sample period), the prior 12-month (that is, from 01 January 2001 to 31 December 2001) cross-sectional constants and payoffs to various style attributes are estimated using Equation 1. The cross-sectional constants and payoffs are then averaged to represent the projections of the constant and payoffs for January 2002. Given the lagged values of the style attributes (31 December 2001) and the projected payoffs for these attributes, the expected return for each sample stock can be computed for January 2002 using Equation 2.

\section{Optimization Objectives}

Two expected return multifactor models are constructed: the Grinold model that has the objective of maximizing the in-sample Grinold (1989) information ratio; and the QH model that has the objective of maximizing the in-sample Qian and Hua (2003) information ratio. The two models differ in terms of the permutations of style attributes that are used to forecast the sample stock returns due to their different optimization objectives. The Grinold (1989) information ratio and the Qian and Hua (2003) information ratio are derived from the information coefficient (IC), which measures the monthly correlation between the realized returns and the forecasted returns. The average IC score for a model is an indication of its forecasting accuracy. Taking into account the number of independent forecasts over the evaluation period (that is, the breadth of the evaluation), Grinold (1989) information ratio is computed using Equation 3. According to Grinold (1989), the model becomes more valuable when its average IC score is not compromised as a result of an increase in its breadth. 
Grinold Information Ratio $=\frac{\sum_{t=1}^{T} \rho_{t}\left(R_{i, t} ; E\left(R_{i, t}\right)\right) \times \sqrt{N_{t}}}{T}$

Where:

$R_{i, t}$ and $E\left(R_{i, t}\right) \quad$ is the realized return for stock $i$ and the model forecasted return for stock $i$ in month $t$;

$\rho_{t}\left(R_{i, t} ; E\left(R_{i, t}\right)\right)$ is the cross-sectional correlation (the IC) between $R_{i, t}$ and $E\left(R_{i, t}\right)$ in month $t$;

$T \quad$ is the number of months in the evaluation period;

$N_{t} \quad$ is the number of sample stock returns being projected in month $t$; and

$\sqrt{N_{t}} \quad$ is the adjustment for the breadth of the forecast in month $t$.

On the other hand, Qian and Hua (2003) argue that a model with a high average IC score adds little value if it made extremely poor forecasts from time to time. Such a model is considered unreliable due to the high volatility of its forecasts. Qian and Hua (2003) provide a remedy to this problem by dividing the average IC score by the standard deviation of the time-series of ICs as depicted in Equation 4. Thus, the model's performance is indirectly proportional to the volatility of its forecasts.

Qian and Hua Information Ratio $=\frac{\overline{I C}}{\sigma_{I C}}$

Where:

$\overline{I C} \quad=\quad$ the average IC score of the model; and

$\sigma_{I C}=$ the volatility of the time-series ICs

The Stepwise Variable Selection Procedure

The stepwise regression procedure of Van Rensburg and Robertson (2003) is initialized by obtaining the Grinold (1989) information ratio score and the Qian and Hua (2003) information ratio score for each of the 38 style attributes. Each style attribute is then ranked according to the scores for the two information ratios respectively. The style attribute that obtains the highest score for each model will be the starting model input for that model. Next, other attributes are used in combination with the starting attribute, one at a time, to obtain their respective 2-factor performance scores. The attribute that contributes the most to the performance score is retained as the second factor in the model. This stepwise procedure is continued, and factors added, until the performance score cannot be improved any further. Thus, the optimal permutations of style attributes employed by each model represent the sets of model inputs that maximize the in-sample scores of the model's stated optimization objective based on the training under the stepwise variable selection procedure proposed by Van Rensburg and Robertson (2003).

\section{The Dynamic Moving-Window Design}

A dynamic moving-window design is employed to update the permutations of style attributes and their expected payoffs for the respective models. Although Haugen and Baker (1996) update the expected factor payoffs in their model to accommodate the time-varying factor payoffs, their actual model inputs are selected once-off in the static in-sample period without being updated periodically. This research undertakes to examine the possibilities of the time-varying of the actual model inputs and the possible improvement of the forecasting power through updating model inputs. A 60-for-12 dynamic moving window is designed to identify the optimal permutations of style attributes for each model to forecast monthly sample stock returns throughout the examination period. Under this design, the inputs of the expected return multifactor models are updated as new data/information arrives and older data/information is discarded. The first training dataset spans the period from 01 January 1997 to 31 December 2001 
to forecast the 12-month returns in 2002. The second training window covers the dataset spanning the period from 01 January 1998 to 31 December 2002. This training window discards the first 12-month data (that is, the data of 1997) and incorporates new 12-month data of 2002 to forecast the 12-month returns in 2003. This training window is repeated a further four times until all monthly sample stock returns in the out-of-sample period from 01 January 2002 to 31 December 2007 is forecasted. The details of the overlapping in-sample periods and their corresponding out-of-sample periods are summarized in Table 2.

Table 2: The Dynamic Moving-Window Design

\begin{tabular}{|l|l|l|}
\hline No. & Overlapping In-Sample (Training) Periods & Corresponding Out-of-Sample (Forecasting) Periods \\
\hline 1 & 01 January 1997 to 31 December 2001 $(60$ months) & 01 January 2002 to 31 December 2002 (12 months) \\
\hline 2 & 01 January 1998 to 31 December 2002 (60 months) & 01 January 2003 to 31 December 2003 (12 months) \\
\hline 3 & 01 January 1999 to 31 December 2003 $(60$ months) & 01 January 2004 to 31 December 2004 (12 months) \\
\hline 4 & 01 January 2000 to 31 December 2004 $(60$ months) & 01 January 2005 to 31 December 2005 (12 months) \\
\hline 5 & 01 January 2001 to 31 December 2005 $(60$ months) & 01 January 2006 to 31 December 2006 (12 months) \\
\hline 6 & 01 January 2002 to 31 December 2006 $(60$ months) & 01 January 2007 to 31 December 2007 (12 months) \\
\hline
\end{tabular}

\section{Issue Regarding Multicollinearity}

In an attempt to identify possible multicollinearity that may arise in building the expected return multifactor models, the monthly cross-correlations of the style attributes are computed and subsequently averaged over the examination period. It should be noted that a significant correlation among independent variables is not a necessary condition for multicollinearity. Following the decision rule of Van Rensburg and Janari (2008), potential multicollinearity problems are detected in the situation where the correlation coefficients between two or more factors are greater than the absolute value of 0.70 . In such instance, the relatively more important attribute, as indicated by the order of the inclusion under the stepwise variable selection procedure, will be retained in the expected return multifactor model. The highly correlated pairs of the style attributes identified include DEBTTMVE and DEBTTBVE; FOREY1 and FOREY2; LAGLPRICE, LPRICE and LSIZE; MOM6 and MOM12; MOM6 and MOM3; and ROE and GROWTH.

\section{EMPIRICAL FINDINGS}

The permutations of the style attributes selected under the stepwise variable selection procedure in each moving-window training period are demonstrated in Table 3. The order in which each of the style attributes are included in the Grinold model and the QH model are displayed in PANEL (A) and PANEL (B) of Table 3 respectively. The style attributes with significant time-series means of their univariate payoffs during the training periods are in italics and highlighted in bold. The style attributes marked with a single asterisk in Table 3 are the attributes in the last iterations of the stepwise regression procedure. These attributes are eliminated because no further improvement in the performance scores is achieved through their inclusions. The style attributes marked with double asterisks are further eliminated from the designated models due to the possibilities of multicollinearity, as a result of their inclusions in the model. As the room for further improvements in the performance scores become minimal towards the last few iterations of the stepwise variable selection procedure, the problem of overfitting through multicollinearity is more likely to occur. This phenomenon is observed in Table 3 as all the style attributes marked with double asterisks are directly above the attributes in the last iterations of the respective moving-window training periods.

\section{Stepwise Variable Selection Procedure}

Examining the identities of the style attributes being included in the respective models in Table 3 reveals that most of the model inputs consist of attributes with significant mean payoffs (in italics and highlighted in bold) during the training window periods. This result supports the use of the univariate score based on the mean factor payoffs to filter out attributes that are less likely to be important in the construction of the expected return multifactor models. Nevertheless, it is apparent that the in-sample performance of the models can be improved by including attributes that are not significant in terms of their univariate mean payoffs in the model construction. On 
the other hand, certain attributes with significant univariate mean payoffs are not necessarily included in the model due to the fact that their contributions to the explanation of the cross-sectional equity returns might overlap with other attributes selected in the prior iterations. For example, attributes related to earnings, such as EY, EARNREV, G12MEPS, FOREY1 and FOREY2, are not selected for inclusion in the multifactor models during the fourth and the fifth moving-window training periods. However, the univariate mean payoffs to these attributes appear to be significant during these training periods in our earlier study (see Hodnett, Hsieh and Van Rensburg (2012)).

In line with the univariate results documented in our earlier study, BVTP and CFTP are the most frequently selected style attributes for both the Grinold model and the $\mathrm{QH}$ model. It is also found that the attributes from the operating performance category that are not tested in our earlier research, such as ROE, ROA and TATURNOVR, are regarded as important elements in the explanation of the JSE stock returns.

Table 3: The Stepwise Variable Selection Results

\begin{tabular}{|c|c|c|c|c|c|c|c|c|c|c|c|c|}
\hline \multicolumn{13}{|c|}{ PANEL (A) Grinold Model: } \\
\hline No. & \multicolumn{2}{|c|}{1997 to 2001} & \multicolumn{2}{|c|}{1998 to 2002} & \multicolumn{2}{|l|}{1999 to 2003} & \multicolumn{2}{|c|}{2000 to 2004} & \multicolumn{2}{|c|}{2001 to 2005} & \multicolumn{2}{|l|}{2002 to 2006} \\
\hline 1 & BVTP & 0.95 & $B V T P$ & 1.29 & $B V T P$ & 1.62 & $B V T P$ & 1.69 & BVTP & 1.53 & LSIZE & 1.32 \\
\hline 2 & FOREY2 & 1.32 & MOM12 & 1.46 & DEBTTBVE & 1.72 & ROE & 1.95 & ROE & 1.85 & MOM12-1 & 1.37 \\
\hline 3 & CFTP & 1.44 & DEBTTBVE & 1.48 & CFTP & 1.85 & CFTP & 2.07 & CFTP & 2.01 & $E Y$ & 1.56 \\
\hline 4 & CURRENTRATIO & 1.47 & $*$ CFTP & 1.44 & ROA & 1.87 & DEBTTMVE & 2.10 & LPRICE & 2.08 & MOM12 & 1.72 \\
\hline 5 & DEBTTMVE & 1.58 & & & *DEBTTMVE & 1.85 & LPRICE & 2.11 & MOM12 & 2.09 & $B V T P$ & 1.77 \\
\hline 6 & EY & 1.67 & & & & & *MOM12 & 2.11 & ROA & 2.17 & ROE & 1.85 \\
\hline 7 & LSIZE & 1.70 & & & & & & & MOM3 & 2.20 & CFTP & 2.01 \\
\hline 8 & *MOM1 & 1.69 & & & & & & & *LSIZE & 2.18 & МOMЗ & 2.04 \\
\hline 9 & & & & & & & & & & & $* * L P R I C E$ & 2.04 \\
\hline 10 & & & & & & & & & & & **LAGLPRICE & 2.08 \\
\hline 11 & & & & & & & & & & & *TATURNOVR & 2.06 \\
\hline \multicolumn{13}{|c|}{ PANEL (B) Qian and Hua (QH) Model: } \\
\hline \begin{tabular}{|l|} 
No. \\
\end{tabular} & \multicolumn{2}{|c|}{1997 to 2001} & \multicolumn{2}{|c|}{1998 to 2002} & \multicolumn{2}{|l|}{\begin{tabular}{|r|}
1999 to 2003 \\
\end{tabular}} & \multicolumn{2}{|c|}{\begin{tabular}{|r|}
2000 to 2004 \\
\end{tabular}} & \multicolumn{2}{|c|}{2001 to 2005} & \multicolumn{2}{|c|}{2002 to 2006} \\
\hline \begin{tabular}{|l|l|l}
1 & \\
\end{tabular} & FOREY2 & 0.61 & $B V T P$ & 0.58 & $B V T P$ & 0.80 & $B V T P$ & 0.88 & $B V T P$ & 0.86 & LPRICE & 0.71 \\
\hline 2 & CFTP & 0.90 & MOM12-1 & 0.86 & MOM12 & 1.01 & MOM12-1 & 1.19 & MOM12-1 & 1.15 & GI2MNPMARGIN & 0.76 \\
\hline 3 & CURRENTRATIO & 1.04 & DEBTTMV & 0.89 & DEBTTBVE & 1.05 & DEBTTBVE & 1.29 & GROWTH & 1.32 & CFTP & 0.93 \\
\hline 4 & $B V T P$ & 1.20 & EY & 0.89 & CFTP & 1.08 & **DEBTTMVE & 1.30 & CFTP & 1.41 & $B V T P$ & 1.02 \\
\hline 5 & EY & 1.39 & CFTP & 0.93 & $E Y$ & 1.12 & *LAGLPRICE & 1.28 & MOM1 & 1.44 & DEBTTBVE & 1.09 \\
\hline 6 & TATURNOVR & 1.47 & *FOREY2 & 0.93 & CFTDEBT & 1.25 & & & ICBT & 1.46 & MOM1 & 1.16 \\
\hline 7 & SALESTP & 1.53 & & & *TATURNOVR & 1.21 & & & G12MCPS & 1.48 & МOM24 & 1.19 \\
\hline 8 & LAGLPRICE & 1.53 & & & & & & & *MOM3 & 1.48 & МOM12 & 1.23 \\
\hline 9 & *MOM1 & 1.53 & & & & & & & & & МOM3 & 1.27 \\
\hline 10 & & & & & & & & & & & *TATURNOVR & 1.24 \\
\hline
\end{tabular}

\section{The Periodic Model Performance}

The periodic performances of the Grinold model and the QH model are evaluated by their respective Grinold (1989) information ratio and the Qian and Hua (2003) information ratio during the evaluation periods. The performance scores of the pre-specified models for the 6 moving-window in-sample periods and their corresponding out-of-sample periods are displayed in PANEL (A) through PANEL (F) of Table 4 respectively. The performance scores for the models that do not filter out any of the highly correlated attributes are shown in parentheses. The aim of removing one or more highly correlated attributes is to mitigate the problem of overfitting and hence improve the robustness and the forecasting power of the model. The study results demonstrated in Table 4 support this view in that the out-of-sample scores are higher for the models that account for the multicollinearity issue.

Overall, Table 4 shows that the out-of-sample performance scores are consistent with their respective insample performance scores in that no large discrepancies are detected between the models' in-sample and out-ofsample performance scores. In many cases, the models' out-of-sample scores appear to be higher than their insample scores. This finding suggests that the permutations of the style attributes selected by the respective models remain robust over the out-of-sample period. This evidence supports the use of the 60-for-12 dynamic moving window design in updating the inputs of expected return multifactor models. 
The consolidated in- and out-of-sample performance scores for the respective models are tabulated in Table 5. The performance scores for the outperforming model is in italics and highlighted in bold. According to Table 5, the QH model achieves the best consolidated in-sample and out-of-sample Qian and Hua (2003) information ratio. Although the in-sample Grinold (1989) information ratio is lower for the QH model, the out-of-sample Grinold (1989) information ratio is higher for the $\mathrm{QH}$ model.

Table 4: The Periodic Model Performance Results

\begin{tabular}{|c|c|c|c|c|}
\hline & & Performance Score & Grinold Model & Qian and Hua (QH) Model \\
\hline \multicolumn{5}{|l|}{ PANEL (A) } \\
\hline 1 Jan 1997 to 31 Dec 2001 & In-Sample & Grinold IR Score & 1.7039 & 1.5352 \\
\hline 1 Jan 2002 to 31 Dec 2002 & Out-of-Sample & Grinold IR Score & 0.9170 & 0.8885 \\
\hline 1 Jan 1997 to 31 Dec 2001 & In-Sample & Qian and Hua IR Score & 1.2632 & 1.5325 \\
\hline 1 Jan 2002 to 31 Dec 2002 & Out-of-Sample & Qian and Hua IR Score & 0.5584 & 0.6333 \\
\hline \multicolumn{5}{|l|}{ PANEL (B) } \\
\hline 1 Jan 1998 to 31 Dec 2002 & In-Sample & Grinold IR Score & 1.4761 & 1.4966 \\
\hline 1 Jan 2003 to 31 Dec 2003 & Out-of-Sample & Grinold IR Score & 1.8629 & 2.2707 \\
\hline 1 Jan 1998 to 31 Dec 2002 & In-Sample & Qian and Hua IR Score & 0.8282 & 0.9295 \\
\hline 1 Jan 2003 to 31 Dec 2003 & Out-of-Sample & Qian and Hua IR Score & 1.5470 & 1.7464 \\
\hline \multicolumn{5}{|l|}{ PANEL (C) } \\
\hline 1 Jan 1999 to 31 Dec 2003 & In-Sample & Grinold IR Score & 1.8655 & 1.4158 \\
\hline 1 Jan 2004 to 31 Dec 2004 & Out-of-Sample & Grinold IR Score & 2.0340 & 2.4938 \\
\hline 1 Jan 1999 to 31 Dec 2003 & In-Sample & Qian and Hua IR Score & 1.0961 & 1.2480 \\
\hline 1 Jan 2004 to 31 Dec 2004 & Out-of-Sample & Qian and Hua IR Score & 1.1714 & 1.1303 \\
\hline \multicolumn{5}{|l|}{ PANEL (D) } \\
\hline 1 Jan 2000 to 31 Dec 2004 & In-Sample & Grinold IR Score & 2.1144 & $1.8762[1.8301]$ \\
\hline 1 Jan 2005 to 31 Dec 2005 & Out-of-Sample & Grinold IR Score & 1.1832 & $1.3822[1.2805]$ \\
\hline 1 Jan 2000 to 31 Dec 2004 & In-Sample & Qian and Hua IR Score & 1.1583 & $1.2857[1.3005]$ \\
\hline 1 Jan 2005 to 31 Dec 2005 & Out-of-Sample & Qian and Hua IR Score & 0.5638 & $1.0005[0.8752]$ \\
\hline \multicolumn{5}{|l|}{ PANEL (E) } \\
\hline 1 Jan 2001 to 31 Dec 2005 & In-Sample & Grinold IR Score & 2.1993 & 1.9054 \\
\hline 1 Jan 2006 to 31 Dec 2006 & Out-of-Sample & Grinold IR Score & 1.4999 & 1.6053 \\
\hline 1 Jan 2001 to 31 Dec 2005 & In-Sample & Qian and Hua IR Score & 1.3455 & 1.4826 \\
\hline 1 Jan 2006 to 31 Dec 2006 & Out-of-Sample & Qian and Hua IR Score & 1.1368 & 1.6951 \\
\hline \multicolumn{5}{|l|}{ PANEL (F) } \\
\hline 1 Jan 2002 to 31 Dec 2006 & In-Sample & Grinold IR Score & $2.0353[2.0780]$ & 1.7564 \\
\hline 1 Jan 2007 to 31 Dec 2007 & Out-of-Sample & Grinold IR Score & 2.2615 [1.7977] & 1.9158 \\
\hline 1 Jan 2002 to 31 Dec 2006 & In-Sample & Qian and Hua IR Score & $1.3376[1.3745]$ & 1.2665 \\
\hline 1 Jan 2007 to 31 Dec 2007 & Out-of-Sample & Qian and Hua IR Score & $1.9808[1.4664]$ & 1.6964 \\
\hline
\end{tabular}


Table 5: Consolidated In-Sample and Out-of-Sample Performance Scores for the Rolling Models

\begin{tabular}{|lcc|}
\hline & Grinold Model & Qian and Hua (QH) Model \\
\hline Grinold (1989) Information Ratio (In-Sample) & & 1.6643 \\
Grinold (1989) Information Ratio (Out-Sample) & 1.8991 & $\mathbf{1 . 7 3 6 7}$ \\
& & \\
Qian and Hua (2003) Information Ratio (In-Sample) & 1.5570 & $\mathbf{1 . 2 9 0 8}$ \\
Qian and Hua (2003) Information Ratio (Out-Sample) & 0.9473 & $\mathbf{1 . 1 1 4 4}$ \\
\hline
\end{tabular}

\section{CONCLUSION}

We construct two expected return multifactor models namely, the Grinold model and the QH model from a pool of 38 style attributes based on the multivariate approach of Haugen and Baker (1996). The models differ in that the Grinold model has an objective to maximize the in-sample Grinold (1989) information ratio while the QH model attempts to maximize the in-sample Qian and Hua (2003) information ratio. The Grinold (1989) information ratio provides an indication of a model's forecasting accuracy with adjustments to the model's breadth. On the other hand, the Qian and Hua (2003) information ratio evaluates the model's forecasting ability with adjustments to the model's forecasting volatility.

The 60-for-12 dynamic moving window design updates the permutations of model inputs every 12 months based on the model trained over the prior 60-month period using the stepwise variable selection procedure of Van Rensburg and Robertson (2003). The performances of the respective models are evaluated over 6 overlapping insample and out-of-sample periods from 01 January 1997 to 31 December 2007. The collective explanatory capabilities of various permutations of style attributes are thus explored. Observing the results of the model inputs selected via the stepwise regression procedure reveals that most of the selected style attributes have significant $t$ statistic for their univariate payoffs. This suggests that the examination of the univariate mean payoffs to style attributes could serve as an effective approach to filter out potentially less important style attributes in building expected return multifactor models. On the contrary, not all attributes that produce significant univariate scores are included in the pre-specified models since their explanatory contributions are overlapped with other attributes included in the prior iterations of the stepwise regression procedure.

In addressing the problems of multicollinearity that result in overfitting the pre-specified models, the study results reveal that the problems of overfitting are likely to occur in the last few iterations of the stepwise variable selection procedure as the room for improvement through further inclusions of model inputs is saturated. This phenomenon is indicated by the fact that highly correlated style attributes are selected by the stepwise regression procedure towards the end of the list of model inputs. It is also found that the models that attempt to address the multicollinearity problem achieved higher out-of-sample scores. This indicates that multicollinearity is a major cause of model overfitting, and the resulting consequence of this is good in-sample, but poor out-of-sample model performance. The analysis of the periodic model performances reveals that the out-of-sample performance scores of the respective models constructed under the dynamic moving-window procedure are consistent with their corresponding in-sample performance scores. Overall, the QH model is found to outperform the Grinold model in terms of both information ratios over the out-of-sample period.

The multivariate analysis of JSE equity style payoffs suggests that successful expected return multifactor models, based on style attributes, can be developed for asset pricing purposes with regular updating of model inputs. The value attributes such as BVTP and CFTP that are found to be important in pricing JSE equity returns documented in the univariate analysis of our prior study remain significant contributors to equity return forecasting in this research.

\section{ACKNOWLEDGEMENT}

This work is supported by the National Research Foundation (NRF) of South Africa. We thank the research office of the University of the Western Cape for their support. 


\section{AUTHOR INFORMATION}

Dr. Kathleen Hodnett is currently a Research Fellow (funded by the National Research Foundation (NRF) of South Africa) in the School of Business and Finance at the University of the Western Cape, South Africa. She is a member of the International Institute of Forecasters (IIF) and an associate member of the South African Institute of Financial Markets (SAIFM).

Dr. Heng-Hsing Hsieh, CFA is the Head of Finance in the School of Business and Finance at the University of the Western Cape, South Africa. He is a member of the International Institute of Forecasters (IIF) and the South African Institute of Financial Markets (SAIFM). E-mail: ahsieh@uwc.ac.za. Corresponding Author

Prof. Paul van Rensburg is the Frank Robb Professor of Finance at the University of Cape Town, South Africa. He is the principal of Salient Quantitative Investment Management. E-mail: paul.vanrensburg@uct.ac.za

\section{REFERENCES}

1. Achour D, Harvey C R, Hopkins G and C Lang (1999), "Firm Characteristics and Investment Strategies in Africa: The Case of South Africa", African Finance Journal, vol. 1, no 1, 1-67

2. Banz R W (1981), "The Relationship between Return and Market Value of Common Stocks", Journal of Financial Economics, vol. 9, 3-18

3. Barberis N, Shleifer A and R Vishny (1998), “A Model of Investor Sentiment”, Journal of Financial Economics, vol. 49, 307-343

4. Basu S (1977), "The Investment Performance of Common Stocks in Relation to Their Price-to-Earnings Ratio: A Test of the Efficient Markets Hypothesis", Journal of Finance, vol. 12, no 1, 129-156

5. Basu S (1983), "The Relationship Between Earnings' Yield, Market Value and The Returns for NYSE Common Stocks: Further Evidence", Journal of Financial Economics, vol. 32, no 3, 663-682

6. Blume M and R Stambaugh (1983), "Biases in Computing Returns: An Application to the Size Effect", Journal of Financial Economics, vol. 28, 19-33

7. Chopra N, Lakonishok J and J R Ritter (1992), "Measuring Abnormal Performance - Do Stocks Overreact?", Journal of Financial Economics, vol. 31, 235-268

8. Daniel K, Hirshleifer D and A Subrahmanyam (1998), "Overconfidence, Arbitrage, and Equilibrium Asset Pricing", Journal of Finance, vol. 56, no 3, 921-965

9. Daniel K, Hirshleifer D and A Subrahmanyam (1998), "Investor Psychology and Security Market Underand Overreactions", Journal of Finance, vol. 53, no 6, 1839-1885

10. Daniel K and S Titman (1997), "Evidence on the Characteristics of Cross Sectional Variation in Share Returns", Journal of Finance, vol. 52, no 1, 1-33

11. Daniel K, Titman S and K Wei (2001), "Explaining the Cross-Section of Stock Returns in Japan: Factors or Characteristics", Journal of Finance, vol. 56, 743-766

12. De Bondt W F M and R H Thaler (1985), "Does the Stock Market Overreact?”, Journal of Finance, vol. 40, no 3, 793-805

13. De Bondt W F M and R H Thaler (1987), "Further Evidence on Investor Overreaction and Stock Market Seasonality", Journal of Finance, vol. 42, no 3, 557-581

14. Fama E F and K R French (1992), "The Cross-Section of Expected Stock Returns", Journal of Finance, vol. 47, 427-465

15. Fama E F and K R French (1993), "Common Risk Factors in the Returns on Stocks and Bonds", Journal of Financial Economics, vol. 33, no 1, 3-56

16. Fama E F and K R French (1996), "Multifactor Explanations of Asset Pricing Anomalies", Journal of Finance, vol. 51, no 4, 55-84

17. Fama E F and K R French (1998), "Value versus Growth: The International Evidence", Journal of Finance, vol. 53, no 6, 1975-1999

18. Fama E F and K R French (2004), "The Capital Asset Pricing Model: Theory and Evidence”, Journal of Economic Perspectives, vol. 18, no 3, 25-46

19. Grinold R C (1989), "The Fundamental Law of Active Management”, The Journal of Portfolio Management, vol. 15, 30-37 
20. Haugen R A (1995), The New Finance: The Case Against Efficient Markets, Prentice Hall, USA

21. Haugen R A and N L Baker (1996), "Commonality in the Determinants of Expected Stock Returns", Journal of Financial Economics, vol. 41, 401-439

22. Haugen R A and N L Baker (2009), "Case Closed", The Handbook of Portfolio Construction: Contemporary Applications of Markowitz, J B Guerard Jr. (ed.), Forthcoming

23. Hodnett K (2010), "Analysis of the Cross-Section of Equity Returns on the JSE Securities Exchange based on Linear and Nonlinear Modelling Techniques", Unpublished Doctoral Thesis, University of Cape Town

24. Hodnett K, Hsieh H and P van Rensburg (2012), "Payoffs to Equity Investment Styles on the JSE Securities Exchange: the Case of South African Equity Market", International Business and Economics Research Journal, vol 11, no 1, 19-32.

25. Jegadeesh N and S Titman (1993), "Returns to Buying Winners and Selling Losers: Implications for Stock Market Efficiency", Journal of Finance, vol. 48, no 1, 65-91

26. Jegadeesh N and S Titman (2001), "Profitability of Momentum Strategies: An Evaluation of Alternative Explanations", Journal of Finance, vol. 56, no 2, 699-720

27. Keim D B (1983), "Size-Related Anomalies and Stock Return Seasonality: Further Empirical Evidence", Journal of Financial Economics, vol. 12, 13-32

28. Lakonishok J, Shleifer A and R W Vishny (1994), "Contrarian Investment, Extrapolation and Risk", Journal of Finance, vol. 49, no 5, 1541-1578

29. Lintner J (1965), "The Valuation of Risky Assets and the Selection of Risky Investments in Stock Portfolios and Capital Budgets ”, Review of Economics and Statistics, vol. 47, no 1, 13-37

30. Litzenberger R and K Ramaswamy (1979), "The Effects of Personal Taxes and Dividends on Capital Asset Prices: Theory and Empirical Evidence", Journal of Financial Economics, vol. 7, 163-195

31. Qian E and R Hua (2003), "The Information Ratio of Active Management”, Putnam Investments

32. Reinganum M R (1981), "Misspecification of Capital Asset Pricing - Empirical Anomalies Based on Earnings' Yields and Market Values", Journal of Financial Economics, vol. 9, 19-46

33. Reinganum M R (1983), "The Anomalous Stock Market Behavior of Small Firms in January - Empirical Tests for Tax-Loss Selling Effects", Journal of Financial Economics, vol. 12, 89-104

34. Rosenberg B, Reid K and R Lanstein (1985), "Persuasive Evidence of Market Inefficiency", Journal of Portfolio Management, vol. 11, 9-1

35. Serra A P (2003), “The Cross-Sectional Determinants of Returns: Evidence from Emerging Markets' Stocks, Journal of Emerging Market Finance, vol. 2, no 2, 123-162

36. Sharpe W F (1964), "Capital Asset Prices: A Theory of Market Equilibrium under Conditions of Risk", Journal of Finance, vol. 19, no 3, 425-442

37. Van Rensburg P and E Janari (2008), "Firm-Specific Attributes and the Cross-Section of Australian Stock Exchange Returns", Journal of Asset Management, vol. 9, no 3, 193-214

38. Van Rensburg P and M Robertson (2003), "Style Characteristics and the Cross-Section of JSE Returns", Investment Analysts Journal, no 57, 1-10

39. Van Rensburg P and M Robertson (2004), Explaining the Cross-Section of Returns in South Africa: Attributes or Factor Loadings?, Journal of Asset Management, vol. 4, no 5, 334-347 
NOTES 